\title{
ARE ECO-DESIGN STRATEGIES IMPLEMENTED IN PRODUCTS? A STUDY ON THE AGREEMENT LEVEL OF INDEPENDENT OBSERVERS
}

\author{
L. Maccioni ${ }^{1, \bigotimes}$, Y. Borgianni ${ }^{1}$, D. C. A. Pigosso ${ }^{2}$ and T. C. McAloone ${ }^{2}$ \\ ${ }^{1}$ Free University of Bozen-Bolzano, Italy, ${ }^{2}$ DTU-Technical University of Denmark, Denmark \\ $\triangle$ lorenzo.maccioni@unibz.it
}

\begin{abstract}
Eco-Design Strategies lead to both enhanced environmental sustainability and product differentiation, which, however, takes place only if observers recognize and value these advantages. To study this aspect, a sample of 40 product pictures has been administered to 12 subjects with experience in eco-design. They were asked to evaluate whether one or more EcoDesign Strategies (in Vezzoli and Manzini's version) were implemented in each depicted product. The outcome of the evaluation was an overall fair agreement. Useful information for eco-design is inferred from nuances of the results.
\end{abstract}

Keywords: sustainable design, product design, design evaluation, ecodesign strategies

\section{Introduction}

In the 1990s, the World Business Council for Sustainable Development has identified seven major eco-efficiency goals driving the development of eco-friendly solutions (DeSimone and Popoff, 2000). Over the last years, many design scholars interpreted these objectives into Eco-Design Strategies (EDSs), i.e. abstract design goals grouping multiple Eco-Design Principles (EDPs) and guidelines aimed to support and drive design towards eco-efficiency.

Bocken et al. (2016) synthesized these concepts in three EDSs focused on managing the flows of resources, i.e. slowing resource flows (optimising product's life), closing resource flows (exploiting circularity), and narrowing flows (optimizing the resource consumption). Moreno et al. (2016) elaborated similar EDSs linking DfX approaches with circular design strategies. Luttropp and Lagestedt (2006) translated environmental goals into product development specifications, which led to the development of the so-called Ten Golden Rules. Fussler and James (1996) suggested the eco-compass headlines, i.e. mass intensity, energy intensity, extending service and function, health and environmental risk, resource conservation, and revalorization. Van Hemel (1999) proposed a series of eight EDSs called Life Design Strategies (LiDS) aimed to support designers with an overview of possible directions for improving products' environmental profiles. These EDSs are (1) Selection of low-impact materials, (2) Reduction of materials usage, (3) Optimization of production techniques, (4) Optimization of distribution system, (5) Reduction of impact during usage, (6) Optimization of initial lifetime, (7) Optimization of end of life and (8) New concept development.

However, among the many proposals for EDSs' schematization, the categories reported in (Vezzoli and Manzini, 2008) are deemed the most comprehensive and exploited by designers (Pigosso et al., 2013). 
These EDS are namely a) Minimising Materials Consumption (MMC); b) Minimising Energy Consumption (MEC); c) Minimising Resources Toxicity and Harmfulness (MRTH) ; d) Optimizing Resources Renewability and Biocompatibility (ORRB); e) Product Lifespan Optimization (PLO); f) Extending the Lifespan of Materials (ELM); g) Facilitating Disassembly (FD).

Vezzoli and Manzini (2008) conceptualized eco-design as a top-down process (Figure 1). This starts with the exploration of EDSs and designers are provided with EDPs, guidelines and explanatory products examples, which are presented in a hierarchic order. Accordingly, if designers implement guidelines or EDPs in their solution, the corresponding EDSs can be considered implemented.

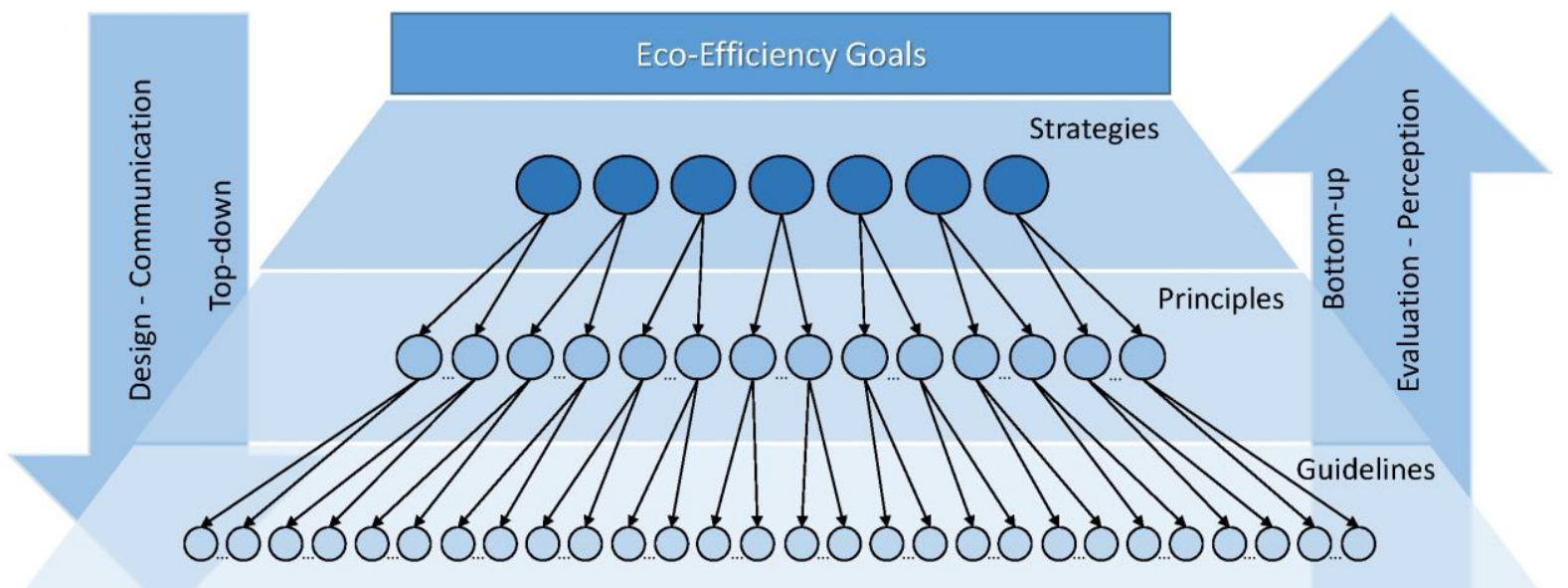

Product/Solution

Figure 1. Eco-design communication (top-down) and evaluation processes (bottom-up)

Design processes that involve the implementation of EDSs are a trigger for product communication and showcasing (Crilly et al., 2004), which aims to stimulate people's positive feelings due to perceivably improved (environmental) performances (She and MacDonald, 2014; She et al., 2018). Unfortunately, in the last decades, this has happened in parallel with green-washing policies, which, in turn, have fuelled a common sense of mistrust in green claims (Segev et al., 2016). Therefore, since new designs will be evaluated and accepted based on their perception of environmental sustainability, communicating the achievement of eco-efficiency goals through design elements might be essential (She et al., 2018; Maccioni et al., 2019a). The focus of the present paper is on those products for which enhancements in terms of environmental sustainability are seen as competing factors and their communication is therefore key to success. It is worth noting that differences could emerge between what the designer intends to communicate and what is actually sensed out the solution. In other words, the characterization of a solution based on the whole set of EDSs that an evaluator perceives implemented (bottom-up process in Figure 1) may differ from the characterization that the designer would aim to develop (top-down process in Figure 1).

Otherwise said, most of the environmental benefits may be difficult to perceive and to communicate even when effectively achieved (She et al., 2018), especially if environmental advantages are gained out of the use phase (Borgianni et al., 2019). Moreover, many studies highlight difficulties in judging what is (more) sustainable and why (She and MacDonald, 2013; She and MacDonald, 2018), even if specific attributes are designed to favour the perception of product environmental sustainability (She and MacDonald, 2013). This is due to both limited knowledge of eco-design by evaluators and intrinsic vagueness in the definition and interpretation of environmental sustainability (She and MacDonald, 2013). Thus, the characterization of a solution based on the perceived implemented EDSs may differ across evaluators. As a result, on the one hand, designers are urged to develop solutions that implement (and communicate) as many EDSs as possible in order to increase the perception of environmental sustainability. On the other hand, different evaluators may perceive different EDSs implemented in the same solution and, therefore, their judgement of environmental sustainability could diverge. 


\section{Objectives, originality of the paper and methodological approach}

In the given context, this paper aims to assess divergences in the evaluation process of implemented EDSs (bottom-up, Figure 1) when the task is performed by eco-design practitioners. This aspect represents an element of originality of the paper, as consumers are often entrusted to express their views on the sustainability and the attractiveness of products, see e.g. (Petersen and Brockhaus, 2017). Moreover, evaluations commonly regard sustainability as a whole and not its components, principles, or strategies at a lower hierarchic level. The approach followed in the present paper, i.e. asking experts to distinguish design principles, is not commonplace in design research. Although a large number of design tools have been developed a posteriori based on the observation of previous designs, e.g. TRIZ (Cascini, 2012; Gibson and Kasravi, 2012) and Design Heuristics (Yilmaz et al., 2016), scholars have scantly perceived the necessity to check whether designers or professional would converge on the identification of applied principles in new designs. This need is instead felt in the field of eco-design, as a culture of what is actually sustainable or environmental-friendly and why should be diffused in order to minimize greenwashing phenomena. The development of such a culture is expectedly in charge of eco-design experts in a first instance. Indeed, if an agreement on product sustainable advantages is not found among people with expertise in eco-design, it is unlikely that evaluation consistency will be met among consumers at large, which supports the relevance of the present work.

\section{Materials and methods}

In order to perform this study, eco-design practitioners trained or doing research at the Technical University of Denmark (DTU) were invited to participate in the experiment. These subjects were supposed to constitute a representative sample of experienced evaluators. More in details, the 12person sample included an associate professor, five Ph.D. students researching sustainability-related topics and six undergraduate students working on eco-design projects. The experiment was conducted at the DTU in a single session and it has been organized in three subsequent phases: an introduction to the EDSs (Vezzoli and Manzini, 2008), an overview of the experimental procedure and the test phase.

During the first introductory phase, each participant was given the Appendix A of the book "Design for Environmental sustainability" (Vezzoli and Manzini, 2008). In this document, provided in a printed version, the EDSs are reported as sets of EDPs and guidelines in the above hierarchic fashion.

An explanation on how EDSs, EDPs, and guidelines were implemented in existing products was provided in about one hour in order to brush up the full spectrum of EDSs, EDPs and guidelines. Subsequently, the test format and rules were explained.

Participants were asked to categorize 20 Product Pairs (PPs), concerning the perceived implementation of the EDSs. PPs (displayed through pictures) include two products of the same commercial category that perform comparable functions; these are intentionally formed by a baseline product and an alternative one in which eco-design efforts were identified in previous studies (Maccioni et al., 2019b). Each product was named with reference to the position in the picture (Left for baseline products, Right for alternatives) and a brief description was provided. An example can be found in Figure 2 and the whole list is in Table 1. The whole set of pictures can be found in (Maccioni et al., 2019b).

The PPs were exposed through an online questionnaire carried out through Google forms, available at the following link. For each PP, the participants were asked to indicate whether, in their opinion, the EDSs were implemented by one (which one), both or none of the products (Figure 2). Products were evaluated as a whole and it was not requested to indicate which product feature drove the indication of the presence of an implemented EDS. To support the evaluation task, participants could consult the hierarchic list of EDSs, EDPs and guidelines previously provided with the following rules.

- If you perceive implemented at least a guideline or an EDP belonging to an EDS, this EDS can be considered implemented

- It is mandatory to select one answer for each EDS

- There are no time constraints. 
Eventually, the residual operational and conceptual questions were clarified through a tutorial based on additional examples. After the beginning the evaluation process, all participants completed their task in about one hour and a half.

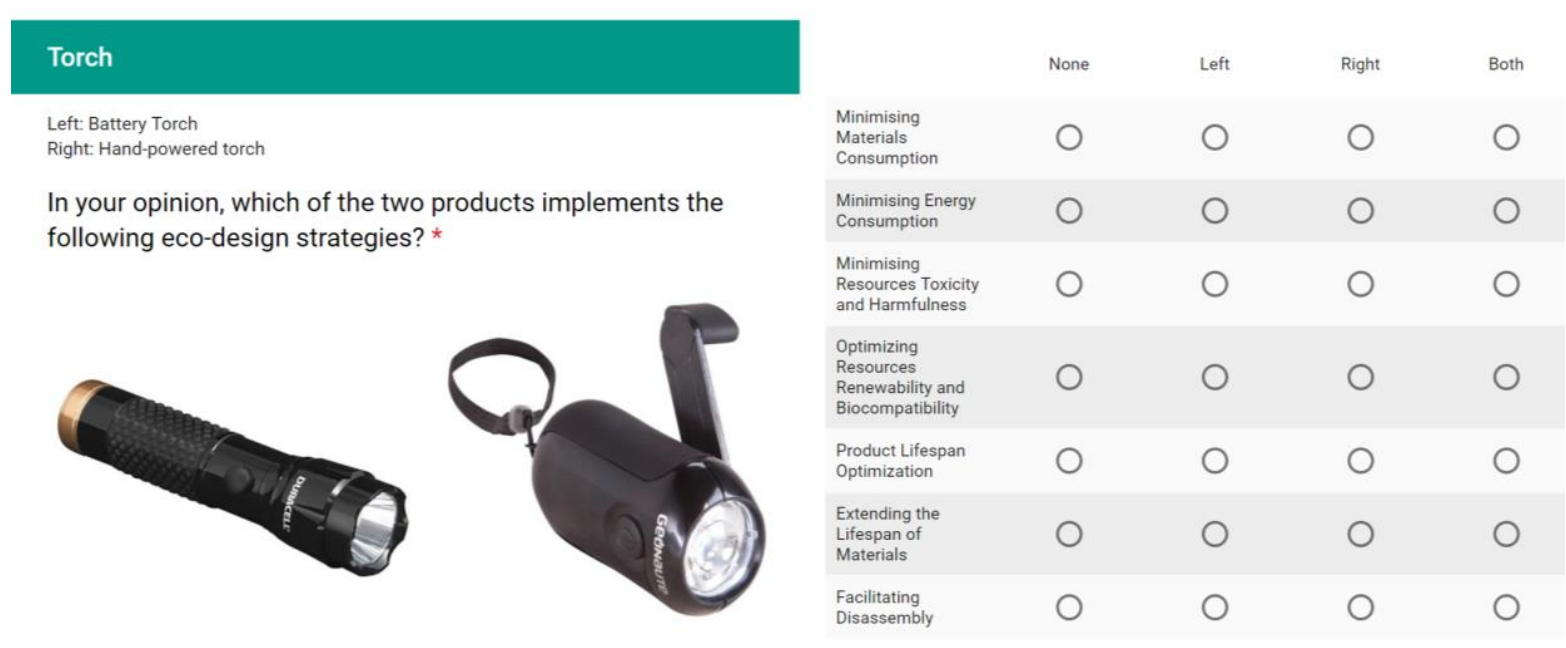

Figure 2. Example of a product pair and the corresponding evaluation template

Table 1. List and description of the illustrated product pairs

\begin{tabular}{|l|l|l|}
\hline \multicolumn{1}{|c|}{ Product Pair } & \multicolumn{1}{|c|}{ Left Product } & \multicolumn{1}{c|}{ Right Product } \\
\hline Single Server Butter & Disposable single-server butter & $\begin{array}{l}\text { Disposable single-server butter that } \\
\text { includes a wooden spoon lid }\end{array}$ \\
\hline Washing-Up Liquid & Washing-Up Liquid & Eco-Refill Washing-Up Liquid \\
\hline Laundry Detergent & $\begin{array}{l}\text { Liquid laundry detergent in a plastic } \\
\text { packaging }\end{array}$ & $\begin{array}{l}\text { Concentrated washing powder in a } \\
\text { cardboard packaging }\end{array}$ \\
\hline Honey gift box & $\begin{array}{l}\text { Honey gift box with "excessive" use of } \\
\text { packaging }\end{array}$ & $\begin{array}{l}\text { Honey gift box with "optimized" use of } \\
\text { packaging }\end{array}$ \\
\hline Printing Toners & $\begin{array}{l}\text { Liquid printing toners in plastic } \\
\text { containers }\end{array}$ & Solid printing toners without containers \\
\hline Toilet papers & Recycled Toilet Papers & Toilet papers without cardboard tube \\
\hline Razor & Disposable Razor & Razor with interchangeable blades \\
\hline Cooker & Gas Cooker & Induction Cooker \\
\hline Coffee cup & Ceramic Coffee cup & Edible coffee cup \\
\hline Milk & $\begin{array}{l}\text { Milk produced more than 1000 km } \\
\text { away from the place of the experiment }\end{array}$ & Milk produced locally \\
\hline Handkerchiefs & Disposable handkerchiefs & Washable handkerchiefs \\
\hline Batteries & Disposable Batteries & Rechargeable Batteries \\
\hline Torch & Battery Torch & Hand-powered torch \\
\hline Toothbrush & Toothbrush & Toothbrush with interchangeable bristles \\
\hline Car & Gasoline Car & Electric Car \\
\hline Water bottle & Water bottle & Space-saving water bottle \\
\hline Shampoo & Liquid shampoo in a plastic container & Solid shampoo in a paper container \\
\hline Couch & Couch & Inflatable Couch \\
\hline Hazelnut Chocolate & Hazelnut chocolate & $\begin{array}{l}\text { Hazelnut chocolate with packaging } \\
\text { reusable as a glass }\end{array}$ \\
\hline Eggs & Eggs in plastic packaging & Eggs in cardboard packaging \\
\hline
\end{tabular}




\section{Analysis methods}

\subsection{Data preparation}

Data collected for PPs evaluation were processed in order to obtain data about EDSs' implementation for each product. Therefore, for each participant, the answers collected through the online questionnaire were transformed in dummy variables (values 1 in case of identified implementation of a specific EDS, 0 otherwise) for Left and Right product as in Table 2. The whole sample of data included 280 observations (7 EDSs x 40 Products) for each of the 12 participants.

Table 2. Criteria to obtain dummy variables for the perceived implementation of eco-design strategies

\begin{tabular}{|c|c|c|}
\hline $\begin{array}{c}\text { Answers in the Google } \\
\text { Format Questionnaire }\end{array}$ & $\begin{array}{c}\text { Elaboration for the } \\
\text { Left Product }\end{array}$ & $\begin{array}{c}\text { Elaboration for the } \\
\text { Right Product }\end{array}$ \\
\hline None & 0 & 0 \\
\hline Left & 1 & 0 \\
\hline Right & 0 & 1 \\
\hline Both & 1 & 1 \\
\hline
\end{tabular}

\subsection{Agreement indicators}

In order to investigate the agreement among the participants (observers), multiple approaches could be used. McHugh (2012) proposes to evaluate the level of agreement among multiple observers for a single answer expressed in percentage. This is calculated through Equation (1) (variable \% Agreementans). The same concept can be intended with a focus on observers instead of specific answers. Accordingly, \%Agreement-part is calculated by means of Equation (2).

$$
\begin{aligned}
& \% \text { Agreement }- \text { ans }=\frac{\sum N^{\circ} \text { of Agreement }}{(\text { observers })[(\text { Observers })-1] / 2} \\
& \% \text { Agreement }- \text { part }=\frac{\sum N^{\circ} \text { of Agreement }}{(\text { Answers })[(\text { Answers })-1] / 2}
\end{aligned}
$$

In both equations, the numerator is the number of times that any couple of observers agrees. In the denominators, the variables Observers and Answers stand for the number of participants (12) and answers taken into consideration to compare two evaluators. In our case study, the denominator in Equation (1) is 66, while the denominator in Equation (2) depends on the number of EDSs considered (more options are possible for comparisons).

Since both percent agreements do not take into account whether the agreement is towards the implementation (1) or the non-implementation (0) of an EDS, an additional indicator has been introduced. For each product and EDS, the \%Implementation is the percentage of the answers affirming the implementation of the EDS in question for the product in question.

An example that explains the difference between \%Agreement-ans and \%Implementation is the following. With reference to an EDS and a product, four observers evaluate the implementation three observers answer 0 (they do not perceive the EDS implemented in the product) while one answers 1 . In this case, the \%Implementation is 0.25 ( 1 evaluator out of 4 perceives that the EDS is implemented), while the \%Agreement is 0.5 (3 agreements on the 6 possible combinations between two distinct evaluators).

The above agreement variables can be expressed just by considering a sole EDS (and all participants) or a sole couple of participants (and potentially all their evaluations). In order to overcome these limitations, it is possible to leverage elaborated Inter-Rater Reliability (IRR) indicators, such as the Fleiss' kappa. The Fleiss' kappa represents the level of agreement in case of more observers and more EDSs (referred to one or more products) (Fleiss, 1971). The result of the calculation, which the authors performed with the statistical software R, is a single IRR coefficient (k) interpreted like in (Landis and Koch, 1977) as a rule of thumb and summarized in Table 3. 
Table 3. Interpretation of Fleiss' kappa (Landis and Koch, 1977)

\begin{tabular}{|l|l|l|l|}
\hline $\begin{array}{l}\text { Fleiss' kappa }(\mathrm{k}) \\
\text { value }\end{array}$ & Interpretation & Fleiss' kappa $(\mathrm{k})$ value & Interpretation \\
\hline$<0$ & Poor Agreement & $0.41-0.60$ & Moderate Agreement \\
\hline $0.01-0.20$ & Slight Agreement & $0.61-0.80$ & Substantial Agreement \\
\hline $0.21-0.40$ & Fair Agreement & $0.81-1.00$ & Almost perfect Agreement \\
\hline
\end{tabular}

\section{Results}

The authors present in this section the results of the analysis they deemed meaningful, which are based on the analysis procedures described in Section 4.

\subsection{Insights from the overall sample}

The results in terms of \%Agreement-part among pairs of observers on the whole answers' database are presented in Table 4 . These coefficients range from 0.62 to 0.81 . The distribution of the results does not highlight outliers. The Fleiss' kappa calculated within the whole answers' database shows a Fair Agreement $(\mathrm{k}=0.34 ; \mathrm{z}=46.2)$. This means that using the whole set of EDSs for characterizing solutions does not lead to levels of agreement such that the implementation of EDSs can be assumed as unanimous.

Table 4. \%Agreement among pairs of observers

\begin{tabular}{|c|c|c|c|c|c|c|c|c|c|c|c|}
\hline & Obs1 & & & & & & & & & & \\
\hline Obs2 & \begin{tabular}{|l|l}
0.69 \\
\end{tabular} & Obs2 & & & & & & & & & \\
\hline Obs3 & \begin{tabular}{|l|}
0.69 \\
\end{tabular} & 0.75 & Obs3 & & & & & & & & \\
\hline Obs4 & \begin{tabular}{|l|l}
0.74 \\
\end{tabular} & 0.74 & 0.72 & Obs4 & & & & & & & \\
\hline Obs5 & \begin{tabular}{|l|l}
0.71 \\
\end{tabular} & 0.77 & 0.81 & 0.75 & Obs5 & & & & & & \\
\hline Obs6 & \begin{tabular}{|l}
0.70 \\
\end{tabular} & 0.75 & 0.77 & 0.77 & 0.81 & Obs6 & & & & & \\
\hline Obs7 & 0.62 & 0.66 & 0.70 & 0.66 & 0.68 & 0.65 & Obs7 & & & & \\
\hline Obs8 & \begin{tabular}{|l|}
0.70 \\
\end{tabular} & 0.74 & 0.75 & 0.70 & \begin{tabular}{|l|}
0.74 \\
\end{tabular} & 0.70 & \begin{tabular}{|l|}
0.68 \\
\end{tabular} & Obs8 & & & \\
\hline Obs9 & \begin{tabular}{|l|l|}
0.66 \\
\end{tabular} & 0.71 & 0.76 & 0.70 & \begin{tabular}{|l}
0.73 \\
\end{tabular} & 0.72 & \begin{tabular}{|l|l}
0.71 \\
\end{tabular} & 0.70 & Obs9 & & \\
\hline Obs10 & \begin{tabular}{|l|}
0.66 \\
\end{tabular} & 0.75 & 0.71 & \begin{tabular}{|l|}
0.73 \\
\end{tabular} & \begin{tabular}{|l|}
0.70 \\
\end{tabular} & \begin{tabular}{|l|}
0.73 \\
\end{tabular} & \begin{tabular}{|l|}
0.69 \\
\end{tabular} & \begin{tabular}{|l|}
0.66 \\
\end{tabular} & 0.70 & Obs10 & \\
\hline Obs11 & \begin{tabular}{|l|l}
0.70 \\
\end{tabular} & 0.77 & 0.79 & 0.76 & \begin{tabular}{|l|l}
0.80 \\
\end{tabular} & 0.77 & \begin{tabular}{|l|l|}
0.69 \\
\end{tabular} & 0.72 & 0.76 & 0.73 & Obs11 \\
\hline Obs12 & \begin{tabular}{|l|}
0.66 \\
\end{tabular} & 0.78 & 0.73 & 0.70 & \begin{tabular}{|l}
0.74 \\
\end{tabular} & 0.70 & \begin{tabular}{|l|l}
0.67 \\
\end{tabular} & 0.72 & 0.71 & 0.68 & 0.81 \\
\hline
\end{tabular}

\subsection{Agreement on implementation and non-implementation}

An additional analysis was carried out concerning the study of \%Agreement-ans in the whole data sample and the potential effect of \% Implementation. Figure 3 subdivides the observations based on the level of $\%$ Agreement-ans. For each of its possible values, the diagram indicates whether the percentage of implementation is greater (grey columns) or lower (black columns) than 0.5. This means distinguishing the cases in which the majority (minority) of evaluators perceive that an EDS is implemented in a product.

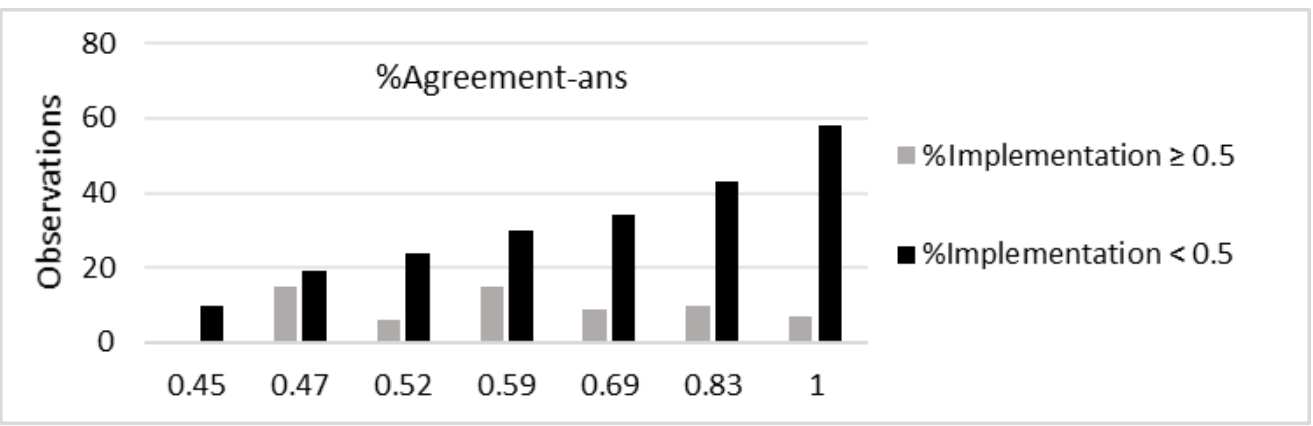

Figure 3. Study of \%Agreement distinguished for different levels of \%Implementation 
It is possible to note that higher levels of agreement are reached when EDSs are diffusedly perceived as non-implemented. This can be interpreted as the overall ease of discerning cases in which EDSs' implementation can be likely excluded, while the perceived presence of an EDS is more largely disputed.

The distribution of observations (62 in total) featuring \%Implementation larger than 0.5 across \%Agreement-ans' values is more uniform than observations concerning low levels of presumed implementation. In addition, the number of observations having \% Implementation values lower than 0.5 is larger than the other set (218 observations in total).

The Fleiss' kappa was then calculated separating the data based on \%Implementation. The calculation led to $\mathrm{k}=0.087 \quad \mathrm{z}=10.4)$ for low implementation values and to $\mathrm{k}=0.029(\mathrm{z}=1.87)$ for high implementation values. In both cases, slight agreement was achieved.

\subsection{Study of the agreement for separate (pairs of) products}

With reference to the whole set of answers, the study of Fleiss' kappa for each product was performed. Results are shown in Table 5. The only solution that achieved a perfect agreement is the toothbrush shown on the left: the evaluators agreed that no EDSs is implemented here in compliance with authors' expectations. Apart from this case, moderate agreement was reached only for the solutions proposed on the right, thus those considered more environmentally sustainable in (Maccioni et al, 2019b). However, the right-hand side products show a better agreement compared to the left-hand ones in only eleven cases out of twenty. It can be inferred that the agreement on presumably more sustainable products is more variable than in baseline ones. Otherwise said, the specific product categories affected the evaluation and the consequent agreement especially for more sustainable alternatives.

Table 5. Study of the Fleiss' kappa for each product evaluated

\begin{tabular}{|l|l|l|l|l|}
\hline Product Pair & $\begin{array}{l}\text { Fleiss' kappa for } \\
\text { Left Product }(\mathrm{z})\end{array}$ & Agreement & $\begin{array}{l}\text { Fleiss' kappa for } \\
\text { Right Product }(\mathrm{z})\end{array}$ & Agreement \\
\hline Single Server Butter & $0.192(4.14)$ & Slight & $0.222(4.78)$ & Fair \\
\hline Washing-Up Liquid & $0.143(3.07)$ & Slight & $0.242(5.21)$ & Fair \\
\hline Laundry Detergent & $0.038(0.83)$ & Slight & $0.141(3.03)$ & Slight \\
\hline Honey gift box & $-0.0107(-0.23)$ & Poor & $0.156(3.34)$ & Slight \\
\hline Printing Toners & $0.174(3.74)$ & Slight & $0.494(10.6)$ & Moderate \\
\hline Toilet papers & $0.236(5.08)$ & Fair & $0.144(3.09)$ & Slight \\
\hline Razor & $-0.012(-0.25)$ & Poor & $0.462(9.93)$ & Moderate \\
\hline Cooker & $0.357(7.68)$ & Fair & $0.196(4.21)$ & Slight \\
\hline Coffee cup & $0.407(8.74)$ & Fair & $0.184(3.96)$ & Slight \\
\hline Milk & $0.060(1.28)$ & Slight & $0.236(5.08)$ & Fair \\
\hline Handkerchiefs & $0.031(0.68)$ & Slight & $0.311(6.68)$ & Fair \\
\hline Batteries & $-0.025(-0.53)$ & Poor & $0.399(8.58)$ & Fair \\
\hline Torch & $0.249(5.35)$ & Fair & $0.266(5.72)$ & Fair \\
\hline Toothbrush & 1.000 & Perfect & $0.587(12.6)$ & Moderate \\
\hline Car & $0.133(2.86)$ & Slight & $0.141(3.02)$ & Slight \\
\hline Water bottle & $0.312(6.71)$ & Fair & $0.179(3.84)$ & Slight \\
\hline Shampoo & $0.03(0.64)$ & Slight & $0.511(11)$ & Moderate \\
\hline Couch & $0.377(8.1)$ & Fair & $0.445(9.56)$ & Moderate \\
\hline Hazelnut Chocolate & $0.066(1.43)$ & Slight & $0.188(4.03)$ & Slight \\
\hline Eggs & $0.010(0.22)$ & Slight & $0.306(6.57)$ & Fair \\
\hline
\end{tabular}

Furthermore, it is worth noting that there is at least one EDS perceived as implemented (\%Implementation $\geq 0.75$ ) that displays a \%Agreement-ans value higher than or equal to 0.59 for each PP. Also if the threshold for \%Agreement-ans is increased to 0.69 and the threshold for \%Implementation is increased to 0.89 , this property keeps being applied diffusedly (17 out of $20 \mathrm{PPs}$ ). These results are inferable also from Figure 4, which graphically depicts the values of \%Implementation. In this picture, spider diagrams 
indicate the \%Implementation for each EDS for each product; black (green) lines feature baseline (more sustainable) products. In many cases and with specific reference to more sustainable products, while one or two EDSs show considerable levels of implementation (and consequently agreement), the residual EDSs resulted quite disputable.
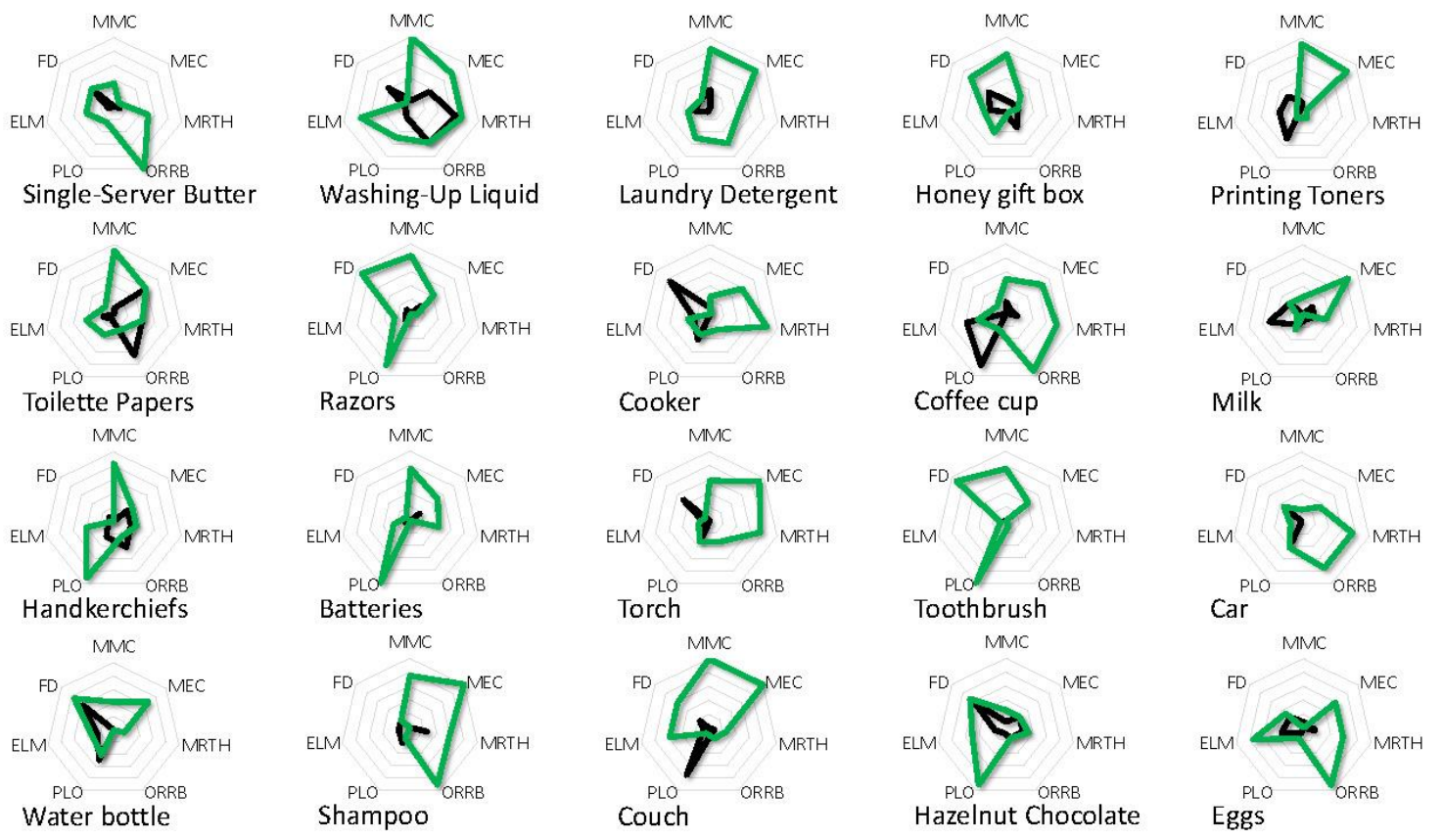

Figure 4. \%Implementation data for each product and eco-design strategies (for acronyms, see Section 1 or Table 6)

\subsection{Study of the agreement for separate eco-design strategies}

Table 6 reports the results of the analysis of Fleiss' kappa performed by considering each EDS separately with the whole set of available data. The same analysis was performed by considering just those cases in which \%Implementation is higher than 0.5, as in Section 5.2.

Table 6. Study of Fleiss' kappa for each eco-design strategy and limited to cases in which \%implementation is higher than 0.5

\begin{tabular}{|l|l|l|l|l|l|}
\hline \multirow{2}{*}{$\begin{array}{l}\text { Eco-Design } \\
\text { Strategy }\end{array}$} & \multicolumn{2}{|l|}{ For each } & \multicolumn{2}{l|}{ \%Implementation >0.5 } \\
\cline { 2 - 6 } & Fleiss' kappa (z) & Agreement & $\mathrm{N}^{\circ}$ of Products & Fleiss' kappa (z) & Agreement \\
\hline MMC & $0.524(26.9)$ & Moderate & 12 & $0.01(0.3)$ & Slight \\
\hline MEC & $0.404(20.8)$ & Fair & 13 & $0.05(1.3)$ & Slight \\
\hline MRTH & $0.272(14)$ & Fair & 8 & $-0.05(-1.3)$ & Poor \\
\hline ORRB & $0.485(24.9)$ & Moderate & 9 & $0.07(1.7)$ & Slight \\
\hline PLO & $0.289(14.9)$ & Fair & 7 & $-0.01(0.1)$ & Poor \\
\hline ELM & $0.109(5.6)$ & Slight & 4 & $-0.006(0.9)$ & Poor \\
\hline FD & $0.252(13)$ & Fair & 9 & $-0.01(-0.2)$ & Poor \\
\hline
\end{tabular}

It is interesting to note that substantial differences emerge between the two analyses; the level of agreement worsens by comparing the two studies reported in Table 6. This confirms that agreement is more commonly reached in evaluating EDSs as not implemented. If the EDSs showing the larger values for agreement in both studies are considered, those do not differ substantially. This means that the agreement worsens quite homogeneously by introducing the constraint on \%Implementation. Consequently, the rationale behind certain EDSs (MMC, ORRB and MEC) seems to be grasped more clearly and more alike than others do. 


\section{Discussion}

In the present research, the data collected was analysed at different levels, i.e. aggregate, level of agreement, products, EDSs (Sections 5.1-5.4). The analysis of the overall agreement shows fair agreement among observers, which is deemed below expectations because all participants had some expertise in ecodesign. Therefore, the environmental characteristics of a solution cannot be described by the present or missing implementation of an acknowledged set of EDSs. An insightful analysis of the results shows a larger agreement on the absence of implemented EDSs. This might be explained as follows. When the environmental advantages of a solution are absent or limited, evaluators tend to agree, but when these advantages are present, it is more difficult to explain them according to known categories.

One of the possible reasons behind large amounts of disagreement can be due to procedural aspects. For example, the (environmental) advantages and disadvantages of products could not result intuitive (see also Maccioni et al., 2019b) and their static form of presentation (pictures) could have reinforced comprehension difficulties. However, the results on the agreement presented in Section 5 show that IRR values are more affected by specific EDSs than single products or PPs. To this respect, it can be inferred that there is a limited shared understanding of how EDSs change designs.

\section{Conclusions, implications and limitations}

Even among eco-design experts, it was not possible to find substantial agreement on which EDSs a product implements (or not) among the whole set of EDSs. According the results of the present study, this has taken place despite the likely shared background of people who work and study in the same environment, i.e. DTU. A good agreement is mainly found in a limited subset of EDSs per product. From a practical perspective, this result could lead to the following interpretations.

- The environmental sustainability of a product is recognized only through the implementation of a limited number of EDSs even if the product actually tends to implement a greater number of them. Based on the results and from the viewpoint of communicating design changes, designers have to consider that MMC, ORRB, and MEC were the most recognized EDSs.

- The implementation of each EDS was evaluated through a dummy variable, which resulted inappropriate, as it was not possible to discern the presence or absence of EDSs clearly. When required, in order to characterize their implementation, it is recommended to describe this presence or absence by values based on multiple evaluations, such as \%Implementation. This kind of potential description is exemplified in Figure 4 through spider diagrams.

The results presented are clearly affected by the following limitations.

- 12 observers were involved; a higher number of subjects could provide more reliable and accurate results, as well as different levels of expertise could be considered in future studies. Markedly, a larger number of participants can help determine the sensitivity of agreement results to the involvement of new evaluators. As well, it could be useful to compare evaluation data across different cohorts of subjects - the authors have already stressed that the participants' belonging to a specific institution was seen as a condition potentially favouring agreement.

- Many considerations were based on the interpretation of the Fleiss' kappa proposed by (Landis and Koch, 1977), which is by no means universally accepted. Likewise, a satisfactory level of agreement depends on studies' objectives.

- Participants were instructed to evaluate positively the implementation of an EDS whenever they could distinguish a corresponding principle or guideline. Different results could have been obtained if the evaluation of the EDSs' implementation had been assessed differently, for instance through a Likert scale. Indeed, despite the instructions, some evaluators could have considered different thresholds to justify the presence of an EDS. Likewise, there was no possibility to judge some changes as actions negatively impacting on some EDSs' objectives.

In addition to addressing the above limitations, future work should target the definition of practices for reducing the asymmetry between eco-designers' and people's perception of products' sustainability. 


\section{Acknowledgement}

The study is supported by the projects EYE-TRACK and few sECOnds funded by the Free University of Bolzano.

\section{References}

Bocken, N.M. et al. (2016), "Product design and business model strategies for a circular economy", Journal of Industrial and Production Engineering, Vol. 33 No. 5, pp. 308-320. https://doi.org/10.1080/21681015.2016. 1172124

Borgianni, Y., Maccioni, L. and Pigosso, D. (2019), "Environmental Lifecycle Hotspots and the Implementation of Eco-design Principles: Does Consistency Pay off?", International Conference on Sustainable Design and Manufacturing, Springer, Singapore, pp. 165-176. https://doi.org/10.1007/978-981-13-9271-9_16

Cascini, G. (2012), "TRIZ-based anticipatory design of future products and processes”, Journal of Integrated Design and Process Science, Vol. 16 No. 3, pp. 29-63. https://doi.org/10.3233/jid-2012-0005

Crilly, N., Moultrie, J. and Clarkson, P.J. (2004), "Seeing things: consumer response to the visual domain in product design”, Design Studies, Vol. 25 No. 6, pp. 547-577. https://doi.org/10.1016/j.destud.2004.03.001

DeSimone, L.D. and Popoff, F. (2000), Eco-efficiency: the business link to sustainable development, MIT press.

Fleiss, J.L. (1971), "Measuring nominal scale agreement among many raters", Psychological bulletin, Vol. 76 No. 5 , pp. 378-382. https://doi.org/10.1037/h0031619

Fussler, C. and James, P. (1996), Eco-innovation: a breakthrough discipline for innovation and sustainability, Pitman, London.

Gibson, J.D. and Kasravi, K. (2012), "Predicting the Future of IT Services with TRIZ”, Journal of Integrated Design and Process Science, Vol. 16 No. 2, pp. 5-14. https://doi.org/10.3233/jid-2012-0015

Landis, J.R. and Koch, G.G. (1977), "The measurement of observer agreement for categorical data", Biometrics, Vol. 33 No. 1, pp. 159-174.

Luttropp, C. and Lagerstedt, J. (2006), "EcoDesign and The Ten Golden Rules: generic advice for merging environmental aspects into product development", Journal of Cleaner Production, Vol. 14 No. 15-16, pp. 13961408. https://doi.org/10.1016/j.jclepro.2005.11.022

Maccioni, L., Borgianni, Y. and Pigosso, D.C. (2019a), "Can the choice of eco-design principles affect products' success?”, Design Science, Vol. 5, p. e25. https://doi.org/10.1017/dsj.2019.24

Maccioni, L., Borgianni, Y. and Basso, D. (2019b), "Value Perception of Green Products: An Exploratory Study Combining Conscious Answers and Unconscious Behavioral Aspects", Sustainability, Vol. 11, p. 1226. https://doi.org/10.3390/su11051226

McHugh, M.L. (2012), "Interrater reliability: the kappa statistic”, Biochemia medica, Vol. 22 No. 3, pp. $276-282$.

Moreno, M. et al. (2016), "A conceptual framework for circular design”, Sustainability, Vol. 8 No. 9, p. 937, https://doi.org/10.3390/su8090937

Petersen, M. and Brockhaus, S. (2017), "Dancing in the dark: Challenges for product developers to improve and communicate product sustainability”, Journal of Cleaner Production, Vol. 161, pp. 345-354, https://doi.org/ 10.1016/j.jclepro.2017.05.127

Pigosso, D.C., Rozenfeld, H. and McAloone, T.C. (2013), "Ecodesign maturity model: a management framework to support ecodesign implementation into manufacturing companies”, Journal of Cleaner Production, Vol. 59, pp. 160-173. https://doi.org/10.1016/j.jclepro.2013.06.040

Segev, S., Fernandes, J. and Hong, C. (2016), "Is your product really green? A content analysis to reassess green advertising”, Journal of Advertising, Vol. 45 No. 1, pp. 85-93. https://doi.org/10.1080/00913367.2015.1083918

She, J. and MacDonald, E. (2013), "Trigger features on prototypes increase preference for sustainability", In ASME 2013 International Design Engineering Technical Conferences and Computers and Information in Engineering Conference, American Society of Mechanical Engineers. p. V005T06A043-V005T06A043.

She, J. and MacDonald, E. (2014), "Priming designers to communicate sustainability", Journal of Mechanical Design, Vol. 136 No. 1, p. 011001. https://doi.org/10.1115/1.4025488

She, J. and MacDonald, E. (2018), "Exploring the Effects of a Product's Sustainability Triggers on Pro-environmental Decision-making", Journal of Mechanical Design, Vol. 140 No. 1, p. 011102. https://doi.org/10.1115/1.4038252

She, J. et al. (2018), "Priming Designers Leads to Prime Designs", In Design Thinking Research. Springer, Cham, pp. 251-273.

Van Hemel, C.G. (1999), EcoDesign empirically explored: Design for environment in Dutch small and medium-sized enterprises, [PhD thesis], Technical University of Delft.

Vezzoli, C. and Manzini, E. (2008), Design for environmental sustainability, Springer, London.

Yilmaz, S. et al. (2016), "Evidence-based design heuristics for idea generation", Design Studies, Vol. 46, pp. 95-124. https://doi.org/10.1016/j.destud.2016.05.001 